\title{
The Status of Intimate Partner Violence-related Education for Nurses in Sri Lanka: A Cross-sectional Survey of the Nursing Curricula
}

\section{Sujatha Seneviratne ${ }^{1 *}$, Sepali Guruge $^{2}$, Sivagurunathan Sivayogan ${ }^{3}$ and Jayantha Jayasiri ${ }^{4}$}

${ }^{1}$ Depatment of Nursing \& Midwifery, ${ }^{3}$ Department of Community Medicine, ${ }^{4}$ Department of Sociology \& Anthropology, University of Sri Jayewardenepura, Sri Lanka

${ }^{2}$ Daphne Cockwell School of Nursing, Ryerson University, Toronto, Canada

\section{Abstract}

Intimate Partner Violence (IPV) results in serious short and long-term health consequences, and is a global health problem. Nurses can play a key role in identifying and addressing the health concerns of women subjected to IPV. Yet, nursing curricula often do not adequately-cover this topic.

The objective of this study was to examine and describe the current status of the IPV-related education for nurses in Sri Lanka.

This study used a descriptive cross-sectional design. A purposive sample of nurse educators from the 24 educational institutions that conduct pre- and post-registration nursing programs in Sri Lanka reviewed their curricula using a pre-tested self-administered questionnaire with closed questions and one open question. Data were analyzed using descriptive statistics and manifest content analysis.

${ }^{*}$ Corresponding should be addressed to Ms. Sujatha Seneviratne, Department of Nursing \& Midwifery, University of Sri Jayewardenepura, Sri Lanka

Email: senevir@sjp.ac.lk

https://orcid.org/0000-0001-7108-7199

(Received 1 17 September 2020; Revised 30th November 2020; Accepted $2^{\text {nd }}$ December 2020 (c) OUSL) 
Results show that none of the curricula included contents on IPV except for two pre-registration programs. Some institutions reported that the topic was addressed sometimes by resource persons during student clinical or field experience. The nursing educators expressed the importance of including IPV content in the nursing curricula. Lack of content, curricular time, nursing educators' lack of competence to teach the topic as well as attitudinal problems, ethical concerns related to women survivors, and lack of continuing education opportunities for nurses were identified as barriers to IPV-related education.

The current IPV education in nursing in Sri Lanka is inadequate. There is an urgent need to incorporate IPV content into nursing curricula and train nursing educators in order to improve nurses' preparedness to care for women experiencing IPV.

Keywords: education, intimate partner violence, nursing curricula, Sri Lanka

\section{Introduction}

Intimate Partner Violence (IPV), defined by the World Health Organization (WHO, 2012) as "any behavior within an intimate relationship that causes physical, psychological and/or sexual harm to those in the relationship" (p. 1), is a global health problem. The IPV affects one third (30\%) of women worldwide (WHO, 2013a). Women subjected to IPV by their partners are presented to health care institutions with a range of serious health problems including fractures, sexually transmitted diseases, unsafe abortions, suicidal attempts and post-traumatic stress disorder (WHO, 2012). Women seeking help for these and other health consequences of IPV tend to visit primary care, mental health care, emergency care, and outpatients' departments more frequently than non-abused women (WHO, 2013a).

Nurses spend most of their time in close contact with patients, thus are in a key position to identify and provide care for women as well as refer them to specialized services (Colombini, Mayhew $\&$ Watts, 2008). Women generally do not reveal that they are subjected to IPV unless specifically asked about it (McGarry \& Nairn, 2015). As such, it is critical that nurses have a solid understanding of IPV, the associated 
health problems, presenting problems and symptoms, and the skills to identify and care for women subjected to IPV (Crombie, Hooker \& Reisenhofer, 2016; Di Giacomo, Cavallo, Bagnasco, Sartini \& Sasso, 2017; Tambağ \& Turan, 2015). Although the importance of such education for nurses at pre and post-registration levels has been recommended and guidelines developed by the WHO (2013a, 2013b, 2017), the nursing curricula in many countries are lacking content related to IPV (AbuTaleb, Dashti, Alasfour, Elshazly \& Kamel, 2012; Beccaria et al., 2013; Bradbury- Jones \& Broadhurst, 2015; Clark, Renner \& Logeais, 2017; Crombie et al., 2016; Doran \& Hutchinson, 2016; Gorman et al., 2016; Hutchinson et al., 2019; Lovi, Hurley \& Hutchinson, 2018); Sundborg, Saleh-Stattin, Wändell \& Törnkvist, 2012).

Some of the effective strategies to IPV-related education include: using interactive learning opportunities (Bradbury-Jones \& Broadhurst, 2015; Wyatt, McClelland \& Spangaro, 2019), providing experiential learning with simulated patients for students to gain confidence in screening for IPV (Blumling, Kameg, Cline, Szpak \& Koller, 2018; Gomez-Fernandez, Goberna-Tricas \& Paya-Sanchez, 2017; Johnson \& Montgomery, 2017; Tufts, Klements \& Karlowicz, 2009), improving communication skills using role plays (Zachor, Chang, Zelazny, Jones \& Miller, 2018), having adequate time and space (Lovi et al., 2018) to address nurses' attitudes towards and stereotypical assumptions about IPV and the victims and perpetrators (Baird, Saito, Eustace \& Creedy, 2018; Di Giacomo et al., 2017; Doran \& Hutchinson, 2016; Rigol-Cuadra, Galbany-Estragué \& Fuentes-Pumarola, 2015), focus on women-centered, compassionate and supportive care (SalettiCuesta, Aizenberg \& Ricci-Cabello, 2018), and cross-disciplinary approaches that capture health, psychological, sociological and ethical perspectives (Gomez-Fernandez et al., 2017).

This paper focused on the current situation of IPV-related education in nursing curricula in Sri Lanka - a middle income country in South Asia, where according to a recent scoping review, the prevalence of IPV ranged between 25-35\% (Guruge et al., 2015).

IPV-related education for nurses in Sri Lanka could possibly take 
place at four levels in nursing education: a three-year diploma nursing education (pre-registration); a four-year (bachelor's) degree program in nursing (pre-registration); a diploma-to-degree program (postregistration), and various specialized courses and programs (postregistration). The Schools of Nursing (SoN) began under the Ministry of Health have been offering three-year nursing education since 1939. Currently there are $17 \mathrm{SoN}$ in the country. The diploma curriculum, last revised in 2004, is followed by all SoN (Jayasekara \& Amarasekara, 2015). Starting in 2005, five state universities began to offer a four-year bachelor's degree programs in nursing, and these programs follow institution-specific nursing curricula (Jayasekara \& Amarasekara, 2015).

The post-registration level education encompasses a diploma-todegree program offered by The Open University of Sri Lanka (OUSL) which began in 1994 (OUSL, 2019), as well as certificates and diploma courses offered to practicing nurses by the Post-Basic College of Nursing (PBCN) that began in 1960 (Marthenesz, 2007). The PBCN is the only government institution that conducts training programs for nurses to develop skills in a range of specialties (Ministry of Health, Nutrition and Indigenous Medicine, 2015) for example, a $1 \frac{1 / 2}{2}$ yearDiploma in Management and Supervision (leading to a position of

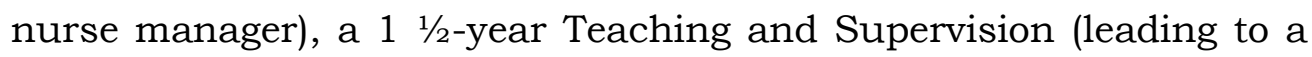
position of a nursing tutor), and six month certificate courses in Mental Health and Psychiatric Nursing and Midwifery training (Jayasekara \& Amarasekara, 2015). The PBCN also provides short courses (3-month each) in other specialized areas of nursing, such as, intensive care nursing, operating theatre nursing and nephrology nursing (Ministry of Health, Nutrition and Indigenous Medicine, 2015). In addition, the $1 \frac{1}{2}$ year post-basic Diploma in Public Health Nursing that leads to a position of Public Health Nursing Sister is conducted at the National Institute of Health Sciences (NIHS) under the Ministry of Health (National Institute of Health Sciences, n.d.).

In 2012, in a qualitative study with 30 nurses from across the country, Guruge reported that nurses in Sri Lanka were inadequately prepared to care for women subjected to IPV (Guruge, 2012). The National Health Strategic Plan 2016-2025 of the Ministry of Health identified a mismatch between the health care needs and the outcomes of the training programs of the health workforce due to non-aligned training 
curricula, and recommended revisions to pre-service curricula and trainer capacity development (Ministry of Health, Sri Lanka, n.d.). However, the policy analysis by Colombini et al. (2018) pointed out that the commitment by the Sri Lankan health sector was low in the initial policy response to violence against women which focused on judicial and legal response. The budget allocations in the 2019 Annual Action Plan of the Ministry of Health, focusing on programs to improve public health, do not include training of nurses related to IPV (Ministry of Health, Nutrition and Indigenous Medicine, 2019). The in-service training programs for nurses were aimed at developing technical, managerial, and soft skills (Ministry of Health and Indigenous Medicine, 2017). Given the Policy Framework and National Plan of Action (2016-2020) to address Sexual and Gender-based Violence (SGBV) in Sri Lanka (Ministry of Women and Child Affairs, 2016), which proposed to introduce a training module for nurses under the Ministry of Health to address this significant health and social problem, nursing curricula in Sri Lanka might have incorporated this content. However, no evidence was found in the recently-published studies on this topic which provided the impetus for this study: to examine and describe the current status of the IPV-related education for nurses in Sri Lanka.

\section{Methodology}

\section{Study Design}

A cross sectional survey with a combined quantitative and qualitative design was used.

\section{Study Settings and Participants}

In total, a purposive sample of 24 participants - one each from the 24 institutes comprising of SoN, universities conducting pre-registration nursing degree programs, PBCN, and the OUSL, took part in the study. All the participants were senior educators in nursing with more than 10 years of experience in teaching (Table 1). 
Table 1. Socio-Demographic Characteristics of Participants $(\mathrm{N}=24)$

\begin{tabular}{llcc}
\hline Characteristic & & Number & (\%) \\
\hline Gender & Male & 05 & 20.8 \\
& Female & 19 & 79.2 \\
Teaching & $10-20$ yrs & 21 & 87.5 \\
Experience & >20 yrs & 03 & 12.5 \\
& SoN (pre-registration) & 17 & 70.8 \\
Type of & University (pre-registration) & 05 & 20.8 \\
Institution & PBCN (post-registration) & 01 & 4.2 \\
& University (post-registration) & 01 & 4.2 \\
\hline
\end{tabular}

\section{The Data Collection Tool}

A data collection tool was developed through a literature review and using WHO guide for curriculum review in nursing courses (WHO, 1985). It was reviewed by two senior educators who are subject experts on IPV. The tool elicited information on content related to IPV (introduction to IPV, health effects of IPV, care for women subjected to IPV, IPV-related services, legal and ethical aspects, counselling skills, attitudes towards IPV, and responses to IPV), under which subject in the curriculum this content was included, academic year, time allocation, resource persons, and methods of teaching and assessment on the topic. An open-ended question was included at the end of the tool to obtain views regarding inclusion of the topic of IPV in nursing curricula. The tool was pre-tested with three nurse educators with more than 10 years of experience, and reorganized to elicit information on diploma, post-basic, and university courses, separately.

\section{Data Collection Process}

Following approval from the Heads of the 24 nursing programs, an invitation letter including information and purpose of the study, and the data collection tool were sent to 24 participants by registered post along with a self-addressed stamped envelope. A reminder was sent by e-mail, and a phone call was given if no response was received within two weeks' time. 


\section{Ethical Considerations}

The study was approved by the Ethics Review Committee, Faculty of Medical Sciences at University of Sri Jayewardenepura and written permission was obtained from the Ministry of Health and the relevant Heads of the study settings. The participants were informed about the voluntary nature of their participation. Confidentiality of their participation and information was maintained by keeping their responses and any identifying information separately in locked file cabinets at the university office of the first author. At the end of the data collection, all identifying information was destroyed. In this paper, participants have been identified by a code number.

\section{Data Analysis}

Data from the 24 completed (returned) forms were analyzed using descriptive statistics. Manifest content analysis (Bengtsson, 2016) was performed on responses of the open question, "staying close to the text" (Kondracki, Wellman, \& Amundson, 2002). The answers to the open-ended question were read several times, to obtain the sense of the whole before it was broken down into smaller meaning units, coded, and categorized according to similarities and differences.

\section{Results}

\section{Pre-registration Nursing Education on IPV}

Content related to IPV was not present in curricula for courses conducted at SoN by the Ministry of Health. However, nine SoN participants $(53 \%)$ reported that the topic was covered during student visits to other institutions for special training as requirements in their diploma course. Of these nine SoN participants, eight reported that the topic was covered during the second-year student visits to Health Units for one month of field training as part of the Community Health Nursing subject. These IPV sessions ranged from 2-12 hours in length, and were conducted in an ad-hoc manner by the guest speakers including the Medical Officer of Health $(\mathrm{MOH})$ and Medical Officer Maternal and Child Health (MOMCH), Medical Officers at NIHS, 
Police/Probation Officers or resource persons from a Nongovernmental organization (NGO) involved in helping affected women. The other (ninth) SoN participant reported that the topic was covered by a Consultant Psychiatrist attached to the National Institute of Mental Health (NIMH) during the psychiatric nursing clinical training. Participants from all (17) SoNs reported that the students were not assessed on the topic. The above findings are illustrated in Table 2.

Table 2. Pre-registration Nursing Education on IPV at SoN

\begin{tabular}{|c|c|c|c|}
\hline Responses of participants & & Number & (\%) \\
\hline \multirow{2}{*}{$\begin{array}{l}\text { Curriculum content related } \\
\text { to IPV }(\mathrm{n}=17)\end{array}$} & Yes & 0 & 0 \\
\hline & No & 17 & 100.0 \\
\hline \multirow{2}{*}{$\begin{array}{l}\text { IPV related teaching } \\
(\mathrm{n}=17)\end{array}$} & Yes & 09 & 52.9 \\
\hline & No & 08 & 47.1 \\
\hline \multirow{3}{*}{$\begin{array}{l}\text { Number of hours taught } \\
(\mathrm{n}=9)\end{array}$} & $1-3$ hours & 04 & 44.4 \\
\hline & 4-7 hours & 04 & 44.4 \\
\hline & $8-12$ hours & 01 & 11.1 \\
\hline \multirow{2}{*}{$\begin{array}{l}\text { Year of study } \\
(\mathrm{n}=9)\end{array}$} & $2^{\text {nd }}$ year & 08 & 88.9 \\
\hline & $2^{\text {nd }} / 3^{\text {rd }}$ year & 01 & 11.1 \\
\hline \multirow[t]{3}{*}{$\begin{array}{l}\text { Teacher/resource person } \\
(\mathrm{n}=9)\end{array}$} & $\begin{array}{l}\text { Internal/Nurse } \\
\text { educator }\end{array}$ & 0 & 0 \\
\hline & $\begin{array}{l}\text { Guest/Medical } \\
\text { Officer* }\end{array}$ & 07 & 77.8 \\
\hline & Guest/other\# & 02 & 22.2 \\
\hline \multirow[t]{3}{*}{ Method of Teaching/learning $(n=9)$} & $\begin{array}{l}\text { Lecture } \\
\text { /Discussion }\end{array}$ & 07 & 77.8 \\
\hline & $\begin{array}{l}\text { Lecture+Group } \\
\text { methods }\end{array}$ & 01 & 11.1 \\
\hline & $\begin{array}{l}\text { Lecture+visits to } \\
\text { service centers }\end{array}$ & 01 & 11.1 \\
\hline \multirow[t]{2}{*}{$\begin{array}{l}\text { Subject under which IPV is taught } \\
(\mathrm{n}=9)\end{array}$} & $\begin{array}{l}\text { Community } \\
\text { Health Nursing } \\
\text { (2nd year) }\end{array}$ & 08 & 88.9 \\
\hline & $\begin{array}{l}\text { Psychiatric } \\
\text { Nursing }\left(2^{\text {nd }} / 3^{\text {rd }}\right. \\
\text { year })\end{array}$ & 01 & 11.1 \\
\hline
\end{tabular}




\begin{tabular}{llll}
\hline $\begin{array}{l}\text { Formal student assessments } \\
(\mathrm{n}=9)\end{array}$ & Yes & 0 & 0 \\
& No & 09 & 100.0
\end{tabular}

*Medical officer: Medical Officer Maternal and Child Health (MOMCH), Medical Officer of Health, (MOH) or Consultant Psychiatrist

\#other: Women in Need (NGO), Police Officer from Children and Women's Bureau/ Probation Officer, Department of Probation and Child care Services.

Two out of five of the state universities offering pre-registration nursing education have reportedly included content related to IPV in its curricula. Of these two, the content was taught during a 2-hour lecture by its own teacher at one university while the other had used a guest lecturer from a service center for women, in a teaching hospital, to teach the content for eight hours including lectures for six hours and 2-hour small group discussions. In addition, educational visits were made by students to the service centre for women for eight hours over a 2-day period. Participants from the two universities reported learning about IPV as part of the Community Health Nursing subject in the $2^{\text {nd }}$ year of the program. One university has reportedly assessed the students on the topic using Multiple Choice Questions in summative evaluation, while the other university participant reported formative methods.

\section{Post-registration Nursing Education on IPV}

According to the participants, five of the main post-registration courses conducted by the Ministry of Health and the diploma-todegree program in nursing at the OUSL did not include content on IPV in their curricula. However, PBCN participant reported that while their curricula did not have IPV content, the topic was addressed by resource persons from the institutions where their students engage in clinical training on mental health and psychiatric nursing (i.e., at NIMH for Courses 1, 2, and 4) or training on public health (i.e., at NIHS for Course 3). The teaching activities were scheduled by the relevant resource persons on voluntary basis, acknowledged by the $\mathrm{PBCN}$. The above findings are illustrated in Table 3. 
Table 3. Post-registration Nursing Education on IPV

\begin{tabular}{|c|c|c|c|c|c|c|}
\hline $\begin{array}{l}\text { Name of the course } \\
\text { and duration }\end{array}$ & $\begin{array}{l}\text { IPV content } \\
\text { in curriculum } \\
\text { (Yes/No) }\end{array}$ & $\begin{array}{l}\text { Duration } \\
\text { (hours) of } \\
\text { teaching }\end{array}$ & $\begin{array}{l}\text { Subject under } \\
\text { which IPV is } \\
\text { addressed }\end{array}$ & $\begin{array}{l}\text { Resource person } \\
\text { /Institution }\end{array}$ & $\begin{array}{l}\text { Teaching/ } \\
\text { Learning } \\
\text { Method }\end{array}$ & $\begin{array}{l}\text { Assessments } \\
\text { (Yes/No) }\end{array}$ \\
\hline $\begin{array}{l}\text { 1. Diploma in Management \& } \\
\text { Supervision ( } 11 / 2 \text { years) }\end{array}$ & No & 05 & Psychiatric Nursing & $\begin{array}{l}\text { Consultant } \\
\text { Psychiatrist/ } \\
\text { NIMH }\end{array}$ & $\begin{array}{l}\text { Lecture/ } \\
\text { Group } \\
\text { Discussion }\end{array}$ & No \\
\hline $\begin{array}{l}\text { 2. Diploma in Teaching \& } \\
\text { Supervision }\left(1 \frac{1}{2} \text { years }\right)\end{array}$ & No & 10 & Psychiatric Nursing & $\begin{array}{l}\text { Consultant } \\
\text { Psychiatrist/ } \\
\text { NIMH }\end{array}$ & $\begin{array}{l}\text { Lecture/ } \\
\text { Group } \\
\text { Discussion }\end{array}$ & No \\
\hline $\begin{array}{l}\text { 3. Diploma in Public Health } \\
\left.\text { Nursing ( } 1 \frac{1 / 2}{2} \text { years }\right)\end{array}$ & No & 12 & Maternal Health & $\begin{array}{l}\text { Medical } \\
\text { professionals, Public } \\
\text { Health Nursing Tutor } \\
\text { /NIHS }\end{array}$ & $\begin{array}{l}\text { Lecture/ } \\
\text { Group } \\
\text { activities }\end{array}$ & No \\
\hline $\begin{array}{l}\text { 4. Certificate in Psychiatric } \\
\text { Nursing (06 Months) }\end{array}$ & No & 05 & $\begin{array}{l}\text { Mental Health and } \\
\text { Psychiatric Nursing }\end{array}$ & $\begin{array}{l}\text { Consultant } \\
\text { Psychiatrist/ } \\
\text { NIMH }\end{array}$ & $\begin{array}{l}\text { Lecture/ } \\
\text { Group } \\
\text { Discussion }\end{array}$ & No \\
\hline $\begin{array}{l}\text { 5. Midwifery training } \\
\text { (06 months) }\end{array}$ & No & - & - & - & - & - \\
\hline $\begin{array}{l}\text { 6. B.Sc.(Hons.) Nursing } \\
\text { (Open \& Distance learning) }\end{array}$ & No & - & - & - & - & - \\
\hline
\end{tabular}

NIMH- National Institute of Mental Health, NIHS- National Institute of Health Sciences 


\section{Responses of Nursing Educators on Inclusion of IPV in Nursing Curricula}

Results of the manifest content analysis of the responses to the openended question of the data collection tool are presented under three categories: Relevance of including IPV in nursing curricula; IPV-related content and its delivery and assessment; and Barriers for inclusion of IPV in nursing curricula. The numbers within parenthesis indicate particular participants. No other demographic information is included alongside to ensure confidentiality of the participants.

Relevance of including IPV in nursing curricula

All participants reported that IPV-related content is relevant and neceszary in nursing curricula to enhance nursing care for women experiencing IPV. Some of the view points on this are provided below:

"IPV is an important aspect that nurses have to deal with inward setting as well as in the community. So, there is no doubt about the relevance of it in the curriculum." (Participant 4)

"Nursing students have no opportunity to learn about this topic but it is relevant for both personal and professional lives of students." (Participant 2)

Participants highlighted women's reluctance to disclose IPV, and as such the importance of healthcare providers being trained to ask and provide timely care.

"IPV is an essential field of study for basic nursing (pre-registration) students as well as post-basic (post-registration) students. In Sri Lanka, many women do not like to expose their hidden sufferings and feelings regarding IPV to others, though they are victims at many times. So as curriculum developers in medical, nursing, and other social fields, should accept the necessity of addressing these issues." (Participant 18) 
"This is a burning issue in urban to rural communities, as majority of territory in Sri Lanka is representing this demography, the severity of the problem is very critical. It is therefore not surprising that women affected by IPV annually have increased use of health care services including emergency units and in-patient hospitalizations." (Participant 15).

Further, the participants suggested that IPV teaching will become mandatory if it is included in the curriculum which is evident in the excerpt below:

"Though we have identified this as an important area to teach, without a curriculum nobody teaches IPV to students. If it is included in our curricula then we are abided by the rules and regulations to cover it in our curricula. So, it is very important to include it in our curricula." (Participant 18)

Yet, some were concerned about the time needed for IPV related teaching. One participant noted that while it is important to include this content it should not take up much space in nursing curricula:

"Few such cases are being reported... it can be included in curriculum as a minor social problem." (Participant 12)

IPV-related curriculum content, its delivery and assessments

The participants expressed the need to include key theoretical and practice content areas on IPV in nursing curricula. Suggestions were made about the content to be delivered, the mode of delivery, the duration, and the program/the level of the as well as changes to the instructional strategies and assessments. Some of these ideas are reflected in the following quotes:

"The essential knowledge and skills the students need to develop should cover especially the legal aspects, communication, and basic counselling skills." (Participant 20)

"I feel that IPV should be included as part of Community Health Nursing sincestudents deal with families and they can understand their situations in real life. Second semester of second year or first semester of third year would be the correct level to 
include the topic since they are mature enough by then." (Participant 8)

"The causes and preventive aspects could be included in the Community Health Nursing and health effects, caring, legal/ethical aspects and counseling aspects of affected persons could be included in Psychiatric Nursing." (Participant 22)

"We can spare 10 hours from the community health nursing course in the $2^{\text {nd }}$ year. If this is not enough, we can find more hours from our (Diploma) curriculum because there are many repetitions." (Participant 10)

The participants also expressed their preferences for ways in which theory and practice could be connected in order to enhance deep learning.

"Reflective interactive sessions are preferred and useful instead of lectures in teaching this type of subject." (Participant 21)

"Just awareness is also not sufficient to handle these issues, some practical experiences and theoretical parts also needed. That means adding this as a compulsory part of their practical exams by utilizing OSPE or OSCE methods." (Participant 18)

Further, as can be seen from the above excerpts, how the assessments should be utilized to enhance competencies in addressing IPV as well as the importance of objectively testing the clinical and practical knowledge and skills acquired during their training were highlighted.

Barriers for inclusion of IPV in nursing curricula

Participants identified many barriers in incorporating IPV into nursing curricula. The key barriers identified included the lack of competence of nursing educators, attitude of the nursing educators, and lack of or limited curricular time and related issues in the existing curriculum were expressed by participants.

"We have more barriers than strengths. Main barriers are lack of 
teachers those who are competent in these areas and attitudinal issues of some teachers." (Participant 18)

"Few others are also requesting to include new topics into the nursing curriculum, but it is not possible to find curricular time, we are facing great difficulties in delivering the existing content within the available time, within the duration of the course." (Participant 5)

The overlaps and repetitions of content in existing curriculum were expressed by the participants as a barrier for incorporating IPV in the curriculum.

"However, the amount of learning on the topic is not enough to develop students' competencies. More time should be allocated, considering that there are many overlapping areas (in other topics) and repetitions in the Diploma curriculum which was not revised after 2004." (Participant 11)

The knowledge and skills for nursing educators to teach IPV- related curricula content were also suggested by the participants to be important barriers in the system for effective delivery of IPV content.

"The lecturers need to have a thorough understanding of the topic; especially about legal aspects and communication skills, related to such incidents (IPV) to teach students." (Participant 21)

"For us to conduct such teaching, we need enough resource persons with improved and new knowledge. We need tutor training programs and curriculum revision. Low payment for external resource personnel also is a problem in getting services from qualified persons. Attitude of health authorities towards developing of nursing specialties is also another barrier." (Participant 15)

Further, the lack of confidence or the reluctance of some nursing educators who have already obtained training to teach the topic was reported.

"Two teachers from each school were trained on this sometime back, by the Ministry of Health. Those who are trained still are not 
confident to do the teaching, they are reluctant." (Participant 17)

The necessity of having discussions with the health authorities in order to overcome the barriers for inclusion of IPV in curriculum was expressed as a possible solution:

"I feel it is a timely need to include this topic in Diploma curriculum, but challenges and barriers to be considered; strategies should be planned to overcome the barriers. Further, discussions are needed with the relevant authorities, probably with the curriculum committee members of the Ministry of Health." (Participant 9)

Participants indicated the need to revise the existing curriculum, for inclusion and allocation of time for new topics subsequently. Lack of continuing education programs for nurses/nurse educators on this topic, and attitudes of health authorities towards developing specialties of nursing were the other barriers reported.

\section{Discussion}

The current situation of IPV education in Sri Lanka includes IPV-related content that is minimally incorporated in pre and post-registration curricula, even though it is recommended by the WHO (2013b) in order to train nurses to identify and support women subjected to IPV. This finding is consistent with the study in Sri Lanka by Guruge in 2012, and several studies from other countries who reported lack of IPV content in formal nursing curricula (Bradbury- Jones \& Broadhurst, 2015; Hutchinson et al., 2019; Lovi et al., 2018; Alsafy et al., 2011; Rocha, Landerdahl, Cortes, Vieira \& Padoin, 2015; Tambağ, \& Turan, 2015). However, the results of this study showed that the IPV knowledge has been imparted to some extent through other sources (during students' clinical and community training in specialized health care settings), though SoN and PBCN curricula do not contain contents on IPV. The inclusion of such content and training has been conducted on an adhoc basis by a variety of non-nursing resource persons without any guidance or prior approval/endorsement from IPV content experts, or any student assessments. Therefore, the participants were unaware of 
the nature and the contents of the said training. The reported mode of assessment is only at recall level, and does not incorporate practical aspects that are stipulated by the WHO (2014). The participants highlighted the importance of IPV education for their students. IPV is a sensitive but critical health and human rights issue that must be addressed by professionals who are trained appropriately (Tufts et al., 2009). As implied by the findings of the current study, the inadequacy of preparation of nurses affect the quality of care they provide to women experiencing IPV (Morse, Lafleur, Fogarty, Mittal \& Cerulli, 2012).

In Sri Lanka, Gender and Women's Health Unit, which is the focal point of National Gender \& Women's Health program under the Ministry of Health, conducts in-service education for selected groups of hospital staff on gender-based violence (Ministry of Health and Indigenous Medicine, 2017), and the National Institute of Mental Health (NIMH) conducts training for health professionals on gender-based violence (NIMH, 2017), where IPV is considered the main component in violence against women (Ministry of Health, Sri Lanka, 2012). Until very recent, the Ministry of Health training programs cater for capacity-building of health care providers attached to One-stop Service Centers for women subjected to violence, named "Mithurupiyasa" (Ministry of Health, Sri Lanka, 2012). In 2017, the training was expanded for curative and preventive staff and a module on GBV was included in the medical curriculum (Family Health Bureau, 2017).

The need to revise the existing nursing curricula in order to incorporate IPV contents and the ways of implementation were stressed by the participants. These findings corroborate with existing evidence from the United States (Tufts et al., 2009), and from Australia (Lovi et al., 2018). Lack of curricular time for the above inclusion was expressed as a barrier in the current study, which also has been raised as a concern in other countries such as Australia (Lovi et al., 2018) and Spain (GomesFernandez et al., 2017). Similarly, study findings from the United Kingdom also report that nursing curricula are already 'squeezed' in terms of content and that all health-related issues cannot be included (Bradbury-Jones \& Broadhurst, 2015). Findings of the current study suggest that overlapping content in curricula could be removed to make space for inclusion of IPV-related content, considering the fact that Diploma in Nursing curriculum was last revised far back in 2004 (Ministry of Health Nutrition and Welfare of Sri Lanka, 2004), and PBCN 
curricula has not been regularly updated to reflect the current needs of the nursing profession (Jayasekara \& Amarasekara, 2015). The results of this study also show that IPV was not included even in most of the newly commenced degree courses.

The current study revealed a lack of competencies among educators to implement IPV content in nursing education, which confirms the findings of Lovi et al. (2018) in Australia. Providing formal education and skills training to nurse educators is essential while helping them to examine various pedagogic approaches to teaching IPV content (GomezFernandez et al., 2017; Rocha et al., 2015). Surprisingly, the nurse educators who had received formal training were reported to be reluctant to teach IPV, which needs to be further investigated to understand the cause of this reluctance. Educational programs for teachers should be developed to address resistant attitudes towards teaching nurses on IPV (Lovi et al., 2018) while simultaneously facilitating the development of self-confidence in teachers (Tufts et al., 2009). Content on legal issues and communication skills were identified as one of key components in education programs on IPV, which is in line with findings from other studies, such as, those by Tufts et al. (2009) and Reis et al. (2010).

The skills in communicating with women who are subjected to IPV are of special importance in the Sri Lankan context where women, in general, do not disclose abuse due to patriarchal gender role beliefs and expectations and stigmatizing attitudes of hospital staff (Guruge, 2012; Jayasuriya et al., 2011; Lee et al., 2015). Therefore, the curricula should include reflective and interactive sessions, and role plays to facilitate students' learning to critically reflect on their own and others' behaviour and attitudes (Tufts et al., 2009), and build trusting relationships to enable women to disclose IPV.

The clinical competencies for nurses related to care for individuals who have experienced IPV were identified in a Delphi study in Taiwan (Lee et al., 2015) in three dimensions comprising a total of 38 items of competencies encompassing knowledge, attitudes, and practice. The participants in the current study proposed to include the content related to IPV into curricula in Community Health Nursing subject and legal and ethical aspects in Psychiatry Nursing subject. Similarly, Gomez- 
Fernandez et al. (2017) reported that competencies in knowledge, skills, and attitudes could be incorporated into curricula in Community Health subject as a public health problem, in the Maternal and Child Health subject as IPV in pregnancy and its impact on the children, in Health Ethics and Legislation to inform legal responsibility and ethical conflicts and under the Health Psychology subject to inform about social inequality derived from patriarchal power. The nursing curricula in Sri Lanka could incorporate such competencies at different levels of study programs to ensure nursing students' awareness of and preparedness to address this critical health problem in order to strengthen the health sector response to IPV.

\section{Limitations of the Study}

While the participants were senior educators in nursing with more than 10 years of experiences in teaching, most of the participants were not involved in actual teaching of IPV at the time of data collection. As a result, some details pertaining to the existing teaching on IPV by external resource persons may not have been captured fully.

\section{Conclusions}

The current situation of IPV training of nurses in Sri Lanka is inadequate in providing care for women subjected to IPV due to problems in inclusion of the topic and related training within nursing curricula.

The pre-registration nursing education curricula in Sri Lanka need to be reviewed to ensure that women who are subjected to IPV are cared for according to the WHOs recommendations. Training of nurses and nursing students on communication and basic counseling skills was suggested for better patient outcomes. Moreover, training of nurse educators as well as continuing education of nurses would be necessary to further enhance competent care for women experiencing IPV. Further qualitative research to explore knowledge, skills, and attitudes of nurses towards women experiencing IPV as well as the experiences of the care received by women subjected to IPV is-warranted in order to identify the nuances related to the gaps in nursing education. 


\section{Acknowledgements}

This work was supported by the University Research Grant, University of Sri Jayewardenepura, Sri Lanka [ASP/01/RE/MED/2015/35].

\section{References}

AbuTaleb, N. I., Dashti, T. A., Alasfour, S. M., Elshazly, M., \& Kamel, M. I. (2012). Knowledge and perception of domestic violence among primary care physicians and nurses: A comparative study. Alexandria Journal of Medicine, 48(1), 83-89. doi: 10.1016/j.ajme.2011.07.014

Alsafy, N.N., Entisar, A., Shurooq, S.A., Medhat, H.A., El-Shazly \& Kamel, M., (2011). Knowledge of Primary care nurses regarding domestic violence, Alexandria Journal of Medicine, 47(2), 173-180. doi: 10.1016/j.ajme.2011.02.002

Baird, K. M., Saito, A. S., Eustace, J., \& Creedy, D. K. (2018). Effectiveness of training to promote routine enquiry for domestic violence by midwives and nurses: A pre-post evaluation study. Women and Birth: Journal of the Australian College of Midwives, 31(4), 285-291. doi:10.1016/j.wombi.2017.10.014

Beccaria, G., Beccaria, L., Dawson, R., Gorman, D., Harris, J. A., \& Hossain, D. (2013). Nursing student's perceptions and understanding of intimate partner violence. Nurse Education Today, 33(8), 907-911. doi:10.1016/j.nedt.2012.08.004

Bengtsson, M., (2016). How to plan and perform a qualitative study using content analysis, Nursing Open, 2, 8-14. doi:10.1016/j.npls.2016.01.001

Blumling A, Kameg K, Cline T, Szpak J., \& Koller C. (2018). Evaluation of a standardized patient simulation on undergraduate nursing students' knowledge and confidence pertaining to intimate partner violence. Journal of Forensic Nursing; 14(3), 174-179. doi:10.1097/JFN.0000000000000212 
Bradbury-Jones, C., \& Broadhurst, K. (2015). Are we failing to prepare nursing and midwifery students to deal with domestic abuse? Findings from a qualitative study. Journal of Advanced Nursing, 71(9), 2062-2072. doi:10.1111/jan.12666

Clark, C. J., Renner, L. M., \& Logeais, M. E. (2020). Intimate partner violence screening and referral practices in an outpatient care setting. Journal of Interpersonal Violence, 35(23-24), 58775888. https://doi.org/10.1177/0886260517724253

Colombini, M., Mayhew, S., \& Watts, C. (2008). Health-sector responses to intimate partner violence in low-and middle-income settings: A review of current models, challenges and opportunities. Bulletin of the World Health Organization, 86, 635-642. doi: 10.2471/BLT.07.045906

Colombini, M., Mayhew, S., Lund, R., Singh, N., Swahnberg, K., Infanti, J.J., Schei, B., \& Wijewardene, K. (2018). Factors shaping political priorities for violence against women-mitigation policies in Sri Lanka. BMC International Health and Human Rights, 18, 22. doi:10.1186/s12914-018-0161-7

Crombie, N., Hooker, L., \& Reisenhofer, S. (2017). Nurse and midwifery education and intimate partner violence: A scoping review. Journal of Clinical Nursing, 26(15-16), 2100-2125. doi:10.1111/jocn.13376

Di Giacomo, P., Cavallo, A., Bagnasco, A., Sartini, M., \& Sasso, L. (2017). Violence against women: Knowledge, attitudes and beliefs of nurses and midwives. Journal of Clinical Nursing, 26(15-16), 2307-2316. doi:10.1111/jocn. 13625

Doran, F., \& Hutchinson, M. (2017). Student nurses' knowledge and attitudes towards domestic violence: Results of survey highlight need for continued attention to undergraduate curriculum. Journal of Clinical Nursing, 26(15-16), 2286-2296. doi:10.1111/jocn.13325

Family Health Bureau (2017). Annual report of the Family Health Bureau 2017, Ministry of Health Sri Lanka, page. 70-71. Retrieved from https://fhb.health.gov.lk/index.php/en/resources/annualreport 
Gómez-Fernández, M. A., Goberna-Tricas, J., \& Payà-Sánchez, M. (2017). Intimate partner violence as a subject of study during the training of nurses and midwives in Catalonia (Spain): A qualitative study. Nurse Education in Practice, 27, 13-21. doi:10.1016/j.nepr.2017.08.001

Gorman, D., Rigol Cuadra, A., Pérez, M. A., Zaplana, I. S., Rodríguez Martín, D., Bujosa, N. T., ......... Hossain, D. (2016). Preparation of Australian and Spanish nursing students for intimate partner violence. Journal of Nursing Education and Practice, 6: 131-135. doi: https://doi.org/10.5430/jnep.v6n12p131

Guruge, S. (2012). Nurses' role in caring for women experiencing intimate partner violence in Sri Lankan context, International Scholarly Research Notices, Article ID 486273, doi:10.5402/2012/486273

Guruge, S., Jayasuriya-Illesinghe, V., Gunawardena, N., \& Perera, J. (2015). Intimate partner violence in Sri Lanka: A scoping review. The Ceylon Medical Journal, 60(4), 133-138.

doi:10.4038/cmj.v60i4.8100

Hutchinson, M., Doran, F., Brown, J, Douglas, T., East, E., Irwin, P., Yates, K., (2019). A cross-sectional study of domestic violence instruction in nursing and midwifery programs: Out of step with community and student expectations, Nurse Education Today, doi:10.1016/j.nedt.2019.104209

Jayasuriya, V., Wijewardena, K., \& Axemo, P. (2011). Intimate partner violence against women in the capital province of Sri Lanka: Prevalence, risk factors, and help seeking. Violence Against Women, 17(8), 1086-1102. doi:10.1177/1077801211417151

Jayasekara R. S. and Amarasekara, T.D., (2015). Nursing education in Sri Lanka; challenges and vision for future, $3^{\text {rd }}$ Annual Worldwide Conference (WNC 2015), GSTF 2015. Retrieved from https://pdfs.semanticscholar.org/cce8/aa00c687d41c9a5c42a7b8 3560710282970a.pdf. 
Johnson, P., \& Montgomery, M. (2017). Improving nursing students' comfort dealing with intimate partner violence. Teaching and Learning in Nursing, 12(4), 286-288. doi: 10.1016/j.teln.2017.07.002

Kondracki, N.L, Wellman, N.S., \& Amundson D.R. (2002). Content analysis: review of methods and their applications in nutrition education. Journal of Nutrition Education and Behavior, 34(4):224230. doi: 10.1016/s1499-4046(06)60097-3.

Lee, F. H., Yang, Y. M., Huang, J. J., Chang, S. C., Wang, H. H., \& Hsieh, H. F. (2015). Clinical competencies of emergency nurses toward violence against women: A delphi study. Journal of Continuing Education in Nursing, 46(6), 272-278. https://doi.org/10.3928/00220124-20150518-03

Lovi, R., Hurley, J., \& Hutchinson, M. (2018). Qualitative findings from an Australian study of inter-partner violence content within undergraduate health curriculum. Nurse Education Today, 70, 1-7. doi: $10.1016 /$ j.nedt.2018.07.012

Marthenesz, T., (2007). History of nursing: Around the world and Sri Lanka (Module1), Faculty of Medical Sciences, University of Sri Jayewardenepura, Nugegoda, Sri Lanka: University of Sri Jayewardenepura.

McGarry, J., \& Nairn, S. (2015). An exploration of the perceptions of emergency department nursing staff towards the role of a domestic abuse nurse specialist: A qualitative study. International Emergency Nursing, 23(2), 65-70. doi: 10.1016/j.ienj.2014.06.003

Morse, D. S., Lafleur, R., Fogarty, C. T., Mittal, M., \& Cerulli, C. (2012). "They told me to leave": How health care providers address intimate partner violence. Journal of the American Board of Family Medicine :JABFM, 25(3), 333-342. doi:10.3122/jabfm.2012.03.110193

Ministry of Health, Sri Lanka (2012). Gender based violence: information booklet for health care providers, Family Health Bureau, Colombo, Author.

Ministry of Health Nutrition and Welfare of Sri Lanka (2004). Curriculum 
for the Basic Nursing Diploma Program, Ministry of Health Nutrition and Welfare of Sri Lanka, Colombo: Author.

Ministry of Health, Nutrition and Indigenous Medicine (2015). Annual Health Bulletin 2015 Sri Lanka, Medical statistics unit, Ministry of Health, Nutrition and Indigenous Medicine, Colombo, Retrieved from

http://www.health.gov.lk/moh_final/english/public/elfinder/files /publications/AH B/2017/AHB\%202015.pdf

Ministry of Health, Sri Lanka, National Health Strategic Master Plan 2016 - $2025 \quad$ (n.d.). Retrieved from http://www.health.gov.lk/moh_final/english/public/elfinder/files / publications /HMP2016-2025/Health\%20\%20Admin\%20$\% 20 \% 20 H R H . p d f$

Ministry of Health, Nutrition and Indigenous Medicine (2019). Annual Action Plan 2019, Planning Unit, Ministry of Health, Nutrition and Indigenous Medicine. Retrieved from http:/ /www.health.gov.lk/moh_final/english/others.php?pid=127

Ministry of Health and Indigenous Medicine, Sri Lanka (2017). Annual Health Bulletin 2017, Ministry of Health and Indigenous Medical Services Sri Lanka, http://www.health.gov.lk/moh_final/english/public/elfinder/files /publications/AHB/2020/AHB_2017.pdf

Ministry of Women and Child Affairs (2016). The Policy Framework and National Plan of Action to address Sexual and Gender-based Violence (SGBV) in Sri Lanka 2016-2020, Ministry of Women and Child Affairs, Colombo. http://gbvforum.lk/rlibrary/document/SGBV\%20National\%20Action\%20Plan.pdf

National Institute of Health Sciences (n.d.). Post-Basic Training programmes. Retrieved from http://nihs.gov.lk/

National Institute of Mental Health (2017). Annual Report, National Institute of Mental Health, Ministry of Health, Sri Lanka, p-14, https://issuu.com/nimh.angoda/docs/annual_report_2017 
Reis M. J. D., Lopes M. H. B. D. M., Higa R., Turato E. R., Chvatal V. L. S., \& Bedone A. J. (2010). Experiences of nurses in health care for female victims of sexual violence. Revista de Saude Publica, 44(2), 325-331. doi: 10.1590/S0034-89102010000200013

Rigol-Cuadra A, Galbany-Estragué P, Fuentes-Pumarola C, BurjalesMartí, M.D., \& Rodríguez-Martín, D, Ballester-Ferrando, D. (2015). Perception of nursing students about couples' violence: knowledge, beliefs and professional role. Revista Latinoamericana de Enfermagem. 23(3):527-534. DOI: 10.1590/01041169.0357 .2584

Rocha BD, Landerdahl M.C., Cortes L.F., Vieira L.T. \& Padoin S.M.M. (2015). Violence against women: Perceptions of nursing students' about the focus on the formation. Investigacion $y$ Educación en Enfermeria, 33(2): 260-268. doi: $10.17533 /$ udea.iee.v33n2a08

Saletti-Cuesta, L., Aizenberg, L. \& Ricci-Cabello, I. (2018). Opinions and experiences of primary healthcare providers regarding violence against women: A systematic review of qualitative studies. Journal of Family Violence. 33, 405-420. doi: 10.1007/s10896-018-9971-6

Sundborg, E. M., Saleh-Stattin, N., Wändell, P. \& Törnkvist, L. (2012) Nurses' preparedness to care for women exposed to intimate partner violence: A quantitative study in primary health care, BMC Nursing, 11:1 http://www.biomedcentral.com/1472-6955/11/1

Tambağ, H., \& Turan, Z. (2015). Ability of nursing students to recognize signs of violence against women. International Journal of Nursing Knowledge, 26(3), 107-112. https://doi.org/10.1111/20473095.12050

The Open University of Sri Lanka (2019). Undergraduate Guide Book (2019/2020), Department of Health Sciences, The Open University of Sri

Lanka, http://www.ou.ac.lk/home/images/Faculty_and_institute/Health Sciences/Downloads/FHS\%20Guidebook\%202019final\%2026.11.19.pdf 
Tufts, K. A., Clements, P. T., \& Karlowicz, K. A. (2009). Integrating intimate partner violence content across curricula: Developing a new generation of nurse educators. Nurse Education Today, 29(1), 4047. https://doi.org/10.1016/j.nedt.2008.06.005

World Health Organization (1985). A guide to curriculum review for basic nursing education: Orientation to primary health care and community health, WHO, Geneva. Retrieved from https://apps.who.int/iris/bitstream/handle/10665/37274/92 41542020_eng.pdf;jsessionid=3565F298D74C7148C526414263 9E724A?sequence $=1$

World Health Organization (2012). Understanding and addressing violence against women, Retrieved from https: / / apps.who.int/iris / bitstream/handle/10665/77432/WH O_RHR_12.36_eng.pdf?sequence $=1$

World Health Organization (2013a). Global and regional estimates of violence against women: prevalence and health effects of intimate partner violence and non-partner sexual violence, World Health Organization, Geneva. Retrieved from https://www.who.int/reproductivehealth/publications/violence /9789241564625/en/

World Health Organization (2013b). Responding to intimate partner violence and sexual violence against women: WHO clinical and policy guidelines, WHO, Geneva. https://www.who.int/reproductivehealth/publications/violence /9789241548595/en/

World Health Organization (2014). Health care for women subjected to intimate partner violence or sexual violence; A clinical handbook, World Health Organization, Geneva. Retrieved from https://www.who.int/reproductivehealth/publications/violence/va w-clinical-handbook/en/

World Health Organization (2017). Strengthening health systems to respond to women subjected to intimate partner violence or sexual violence,

A manual for health managers, 
https://apps.who.int/iris/bitstream/handle/10665/259489/9789 241513005-eng.pdf

Wyatt, T., McClelland, M. L., \& Spangaro, J. (2019). Readiness of newly licensed associated degree registered nurses to screen for domestic violence. Nurse Education in Practice, 35, 75-82. doi: $10.1016 /$ j.nepr.2018.12.010

Zachor, H., Chang, J. C., Zelazny, S., Jones, K. A., \& Miller, E. (2018). Training reproductive health providers to talk about intimate partner violence and reproductive coercion: An exploratory study. Health Education Research, 33(2), 175-185. https://doi.org/10.1093/her/cyy007 